See discussions, stats, and author profiles for this publication at: https://www.researchgate.net/publication/244156717

\title{
Modelling Fluidized Bed Elutriation of Fine Particles
}

Article in Powder Technology · November 1999

DOI: 10.1016/S0032-5910(99)00057-1

CITATIONS

29

3 authors, including:

Domingo Santana

University Carlos III de Madrid

106 PUBLICATIONS 1,050 CITATIONS

SEE PROFILE
READS

757

Some of the authors of this publication are also working on these related projects:

Project $\quad$ Optimization of solar thermal plants, transient analysis and design of eccentric bayonet receivers (ExTraSol) View project

Project $\quad$ Análisis de tensiones y deformaciones en los receptores solares centrales View project 


\title{
Modelling fluidized bed elutriation of fine particles
}

\author{
D. Santana, J.M. Rodríguez ${ }^{1}$, A. Macías-Machín * \\ Grupo EMA, ETSII de Las Palmas, Universidad de Las Palmas de Gran Canaria, Tafira Baja s / n, Las Palmas de Gran Canaria, Canary Islands, 35017, \\ Spain
}

Received 30 October 1998; received in revised form 10 March 1999; accepted 10 March 1999

\begin{abstract}
Experimental work with Geldart groups A and C powders was carried out in a 6.4-cm i.d. column fluidized batchwise at superficial velocities between 0.24 and $0.6 \mathrm{~m} \mathrm{~s}^{-1}$. A new model was proposed to account for elutriation and attrition based on the assumption that the generation of fines by attrition is a nonlinear function of time and depends on the percentage of agglomerated fines. Elutriation rate constants and attrition rates were evaluated at various particle mixing ratios and it could be observed that the entrainment rate at low air velocities was affected by interparticles adhesion forces. (C) 1999 Elsevier Science S.A. All rights reserved.
\end{abstract}

Keywords: Elutriation; Fluidized beds; Entrainment; Modelling

\section{Introduction}

The understanding of the elutriation process of solid particles has become increasingly important in recent years not only owing to the increasing use of fluidized bed techniques in industrial plant operations but also because of the convenience of this process as a method of particle generation used for the proper design of separation equipment such as cyclones, granular filters, scrubbers, ceramic filters and others [1].

Several investigators have made important contributions to the understanding of the mechanism of elutriation. Initial results were presented in Refs. [2-4]. These investigators studied the rate of elutriation from beds of two different particle sizes. System variables such as the gas velocity, particle size and concentration of fines, solid and gas properties, etc., were empirically related to the elutriation constant.

Other relevant research in this field has been carried out by Kunii and Levenspiel [5], Geldart et al. [6], Wen and Chen [7] and Yates and Newton [8]. Later, Geldart et al. [9] and Baeyens et al. [10] presented results on the elutriation from beds of fine powders, where interparticles adhesion

\footnotetext{
* Corresponding author. Tel.: +34-928-45-1900; Fax: +34-928-45 1846; E-mail: amacias@cicei.ulpgc.es

${ }^{1}$ On leave from University of Salamanca, Spain.
}

forces are shown to have an important influence on the elutriation rate

Geldart et al. [9] considered that the addition of a small quantity of Geldart-C particles (cohesive difficult-to-fluidize) caused a decrease in elutriation due to fines adhering to the large particles, working together instead of working independently. On the contrary, if a large quantity of Geldart-C particles were added, the bed would become cohesive, thus, decreasing in bubbling and increasing in formation of channels.

Smolders and Baeyens [11] conducted studies of entrainment of Geldart groups $\mathrm{A}$ and $\mathrm{C}$ powders showing that the entrainment rate at low velocities was strongly reduced by interparticles adhesion forces when a vibrating bed and different freeboard geometries were used.

Jaraiz et al. [12] used the vibration of the fluidized bed and showed vibration is useful in fluidized beds with very small particles, smaller than about $30 \mu \mathrm{m}$, because relatively strong interparticles forces develop which lead to particle agglomeration with channelling of gas and minimum fluidizing velocities much higher than predicted by theory. Fortunately, vibration of the fluidized bed overcomes this poor contacting by helping to break up those agglomerates. Channelling diminishes or disappears, and a higher pressure drop across the bed is observed indicating better gas/solid contacting and more complete suspension of the particles.

Whether breakage of particles in a fluidized bed occurs by abrasion or fragmentation depends upon a wide range 
of factors which include particle morphology and particle strength as well as fluid-dynamic-induced forces exerted on the particles in suspension [13]. Ayazi Shamlou et al. [14] indicate that the breakage of bed material can occur by purely hydrodynamic effects in the bed and Arena et al. [15] indicate that the attrition during the fluidized combustion of a bituminous coal depends on fluidizing velocity and size of sand and coal in the bed.

In this paper, the attrition term is used to define the process in which small particles adhered to bigger ones and small particle agglomerates are dispersed due to the action of hydrodynamic forces. The particles are later found in the bed in the form of free fines.

Bortzmeyer and Goimard [16] have investigated the relationship between the attrition tendency of agglomerates and their mechanical behaviour and evaluated the influence of the particle characteristics. They used three $\mathrm{CaCO}_{3}$ powders of different shapes and sizes one of which exhibited a far higher attrition rate than others. It was found that this behaviour was related to the surface properties of the agglomerates.

Yadav et al. [17] showed that increase in fines, found in Geldart group C, affects both elutriation and fluidization characteristics, being observed that the agglomerations of fines with coarse particles or among them depended on the percentage of fines in the bed.

Arena et al. [15], Chirone et al. [18] and Liu and Kimura [19] observed that the fine particles generated by attrition in beds of mixtures of fine and coarse particles controlled elutriation.

Because published correlations on entrainment relate mainly to systems of large particles in which interparticle forces have a minimal effect, they do not adequately predict the entrainment of very fine particles [11] and because these correlations do not take into account particle agglomeration in the bed [20]. There is a need for a modelling approach.

Clearly, what is needed initially is the adoption of an approach that shows that attrition is closely related to the percentage of particles agglomerated in the bed, and that the generation of fines by attrition is not independent of the percentage of fines agglomerated in the bed and equal to a constant as some researchers assert [19,21,22].

In a pioneer paper, Leva [3] used an equation similar to the first order chemical reaction equation in order to model the elutriation process in fluidized beds where the decrease in the concentration of fines in the bed is proportional to the concentration of fines remaining in the bed. Then, Wen and Hashinger [23] used the former model but they suggested that the decrease in fines could be considered proportional to the concentration of fines remaining in the bed and inversely proportional to the bed height, where the proportionality constant is the elutriation rate constant which is independent of the bed cross-sectional area.

After that, Colakyan et al. [21] integrated fines generation process in the bed (attrition) into the first order equation, supposing that attrition rate constant or fines generation constant would be constant with time. Finally, Liu and Kimura [19] used this later model, dividing the fines remaining in the bed into three states (freely moving fines, fines attached to large particles and fines agglomerations).

In literature, there are other models which are not based on the first order equation. These models also try to be near to elutriation and attrition process in fluidized beds, in which a division in the states of fines remaining in the bed is made, being distinguished freely moving fines and agglomerates [17,20].

The aim of this investigation was to determine a model that describes the carryover of fines from mixtures where attrition is related to the percentage of particles agglomerated in the bed, verifying that modelling of the attrition process is due to purely hydrodynamic forces [14], and recognising that the reduction of agglomerated fines in the bed by attrition is not a linear function but exhibit an exponential decay with time.

Experimental data are reported which allows us to test the model experimentally. Theoretical expressions are developed for the elutriation rate constants and its relationship which depends on the percentage of particles agglomerated in the bed. The applicability of the governing equations is discussed in the light of the experimental data obtained in this work and as reported by others.

\section{Modelling of elutriation}

A number of models have been proposed on the basis of a first order equation to describe elutriation from a fluidized bed $[3,19,21,23]$. Colakyan et al. [21] have presented a model which accounts for attrition in addition to elutriation. Their model reads:

$$
\begin{aligned}
& -\frac{\mathrm{d} W_{i}}{\mathrm{~d} t}=k_{i} A_{\mathrm{b}} \frac{W_{i}}{W_{\mathrm{b}}}-R_{i} \\
& \frac{\mathrm{d} W_{\mathrm{e}, i}}{\mathrm{~d} t}=k_{i} A_{\mathrm{b}} \frac{W_{i}}{W_{\mathrm{b}}}
\end{aligned}
$$

where $W_{i}$ is the mass of particles size $i$ remaining in the bed at time $t, W_{\mathrm{b}}$ is the total mass of solids in the bed, $A_{\mathrm{b}}$ is the cross-sectional area of the bed, $k_{i}$ is the elutriation rate constant for particles of size $i, W_{\mathrm{e}, i}$ is the weight of particles of size $i$ which have been elutriated from the bed at time $t$ and $R_{i}$ is the rate of attrition for particles of size $i$ and this parameter is assumed to be constant.

Integrating Eqs. (1) and (2) with the initial conditions: $W_{\mathrm{e}, i}=0$ and $W_{i}=W_{\mathrm{b}, i}$ at $t=0$, we obtain:

$W_{\mathrm{e}, i}=\left(W_{\mathrm{b}, i}-\frac{R_{i}^{*}}{k_{i}^{*}}\right)\left(1-\mathrm{e}^{-k_{i}^{*} t}\right)+R_{i}^{*} t$ 
where $W_{\mathrm{b}, i}$ is the initial mass of particles size $i$ in the bed and where

$k_{i}^{*}=\frac{k_{i} A_{\mathrm{b}}}{W_{\mathrm{b}}}$

$R_{i}^{*}=\frac{R_{i}}{W_{\mathrm{b}}}$

A variation of this model is given by Liu and Kimura [19] where the elutriation rate constant and attrition rates were evaluated at various particles mixing ratios and gas velocities.

Observing Eq. (3) for $t \gg 0$ [21] illustrates how this equation approaches an asymptotic equation which however is linear with time:

$W_{\mathrm{e}, i}=\left(W_{\mathrm{b}, i}-\frac{R_{i}^{*}}{k_{i}^{*}}\right)+R_{i}^{*} t$

For $t=\infty$, Eq. (3) or Eq. (6) result in:

$\lim _{t \rightarrow \infty} W_{\mathrm{e}, i}=\infty$

This limit must however be $W_{\mathrm{b}, i}$, the initial weight of particle size $i$ in the bed since only the weight of charged particles can be elutriated from the bed.

This is due to the fact that the generation of fines by attrition in $[19,21]$ is independent of the mass of charged particles in the bed. However, according to Ayazi Shamlou et al. [14], the fine particles generation by attrition in the bed is a function of the percentage of the agglomerated particles which remain in the bed. Therefore, the generation of fines by attrition is not independent of the mass of charged particles as is said in Refs. [19,21].

Attrition increases the number of the free flowing particles and reduces the agglomerated fines. Knowing the particle population is essential in the assessment of the bed performance and particle entrainment or elutriation [7,24].

Therefore, a fluidized bed with agglomerate materials can not be designed appropriately until the attrition activity is quantified [13]. In this work, attrition refers to the process of removal fines from the surface of the parent material so that there is only a gradual decrease in the percentage of agglomerated fines in the bed. Also, it has been known that experimental data obtained in the attrition process suggest a nonlinear rate of increase in the mass of fines generated as a function of operating time [14]. Similar findings are given in Ref. [13] where the particle attrition phenomenon in a fluidized bed indicates that freshly ground particles usually have an initial period of rapid attrition before the attrition pace slows down to a certain steady level.

Studies on mixing of fine powders with large particles in a fluidized bed recognise that the fine powder not only forms agglomerates [14,17,23-25] but also coats or attaches to the large particles $[9,26]$. It has also been prospected that the majority of fine particles in the bed agglomerated in large clusters which are easily fluidized and a small fraction of fine particles remain as free fines [19]. Other relevant investigation on the attrition process and its relation with time have been carried out by and Bortzmeyer and Goimard [16], based on Johnson-Mehl's equation. On the basis of these findings, one may make the following assumptions to describe the fluidization and elutriation process:

- The attrition is a process of removal fines from the surface of a parent material and/or clusters dispersion.

- The generation of fines by attrition is a nonlinear function of time and depends on the percentage of agglomerated fines.

- The attrition of the large particles (bed material) is negligible.

- Fine particles in the bed are in one of the following forms.

-elutriable freely moving fines

-agglomerates of fines and fines attached to large particles

Then, our model reads:

$$
\begin{aligned}
& -\frac{\mathrm{d} W_{\mathrm{f}, i}}{\mathrm{~d} t}=k_{i} A_{\mathrm{b}} \frac{W_{\mathrm{f}, i}}{W_{\mathrm{b}}}-R_{i} \frac{W_{\mathrm{a}, i}}{W_{\mathrm{b}}} \\
& -\frac{\mathrm{d} W_{\mathrm{a}, i}}{\mathrm{~d} t}=R_{i} \frac{W_{\mathrm{a}, i}}{W_{\mathrm{b}}}
\end{aligned}
$$

$\frac{\mathrm{d} W_{\mathrm{e}, i}}{\mathrm{~d} t}=k_{i} A_{\mathrm{b}} \frac{W_{\mathrm{f}, i}}{W_{\mathrm{b}}}$

where $W_{\mathrm{f}, i}$ is the mass of elutriable freely moving fines of size $i, W_{\mathrm{a}, i}$ is the mass of agglomerated fines of size $i$, that remain in the bed at time $t, W_{\mathrm{e}, i}$ is the cumulative mass of fine particles of size $i$ carried out of the bed, $A_{\mathrm{b}}$ is the cross-sectional area of the bed and $W_{\mathrm{b}}$ is the total mass of particles which are initially charged in the bed. $R_{i}$ is the rate of attrition for particles of size $i$ and $k_{i}$ is the elutriation rate constant for particles of size $i$.

At this moment, it must be taken into account some important aspects from the later three equations. The mass of free fines which remain in the bed decreases by elutriation and increases by the production of fines from the breaking of agglomerates as describe in Eq. (8). The left side of Eq. (9) is the rate of decrease in agglomerates or the rate of free fines generation by attrition, free fines generation follows a first order equation used to model the attrition in fluidized beds in bubble regime [27] and for fluidized beds in slugging regime [28]. It is important to notice the attrition rate constant that regulates the mass transfer from agglomerated fines to free fines.

The elutriation rate (left side of Eq. (10)) is proportional to the percentage of free fines in the bed, to the elutriation rate constant and to the cross-sectional area of the bed [29]. 
On the other hand, it is important to point out that the reduction of agglomerate particles by attrition is not linear but an exponential decay.

Integrating Eqs. (6)-(8) with the following initial conditions at $t=0$ :

$W_{\mathrm{f}, i}=W_{\mathrm{f}, 0 i}$

$W_{\mathrm{a}, i}=W_{\mathrm{a}, 0 i}=W_{\mathrm{b}, i}-W_{\mathrm{f}, 0 i}$

$W_{\mathrm{e}, i}=0$

we obtain:

$$
\begin{aligned}
W_{\mathrm{e}, i}= & W_{\mathrm{f}, 0 i}\left(1-\mathrm{e}^{-k_{i}^{*} t}\right)+\frac{W_{\mathrm{b}, i}-W_{\mathrm{f}, 0 i}}{R_{i}^{*}-k_{i}^{*}}\left(R_{i}^{*}\left(1-\mathrm{e}^{-k_{i}^{*} t}\right)\right. \\
& \left.-k_{i}^{*}\left(1-\mathrm{e}^{-R_{i}^{*} t}\right)\right),
\end{aligned}
$$

where $k_{i}^{*}$ and $R_{i}^{*}$ are defined in Eqs. (4) and (5), respectively.

We can limit Eq. (12) when $t \rightarrow \infty$, since only the fines particles added to the bed can be elutriated:

$\lim _{t \rightarrow \infty} W_{\mathrm{e}, i}=W_{\mathrm{b}, i}$

The previous initial conditions are only true if the process is due to the removal of cluster fines or larger particles. When this model is used with a different type of attrition, due to the breaking of asperities of larger particles or due to fragmentation, it is necessary to use it cautiously because the weight of fine which are finally elutriated can be unknown.
In order to determine the model constants, a simple Newton-Ralston algorithm [30] was used to minimize the function:

$f_{\text {err }}=\sum_{t=1}^{n}\left(W_{\text {cal }}(t)-W_{\text {mod }}(t)\right)^{2}$

And the expression of the rate of overall attrition, elutriation and initial mass of elutriable freely moving fines will be:

$$
\begin{aligned}
& W_{\mathrm{f}, 0}=\sum_{i=1}^{n} W_{\mathrm{f}, 0 i} \\
& k=\sum_{i=1}^{n} k_{i} \frac{W_{\mathrm{f}, 0 i}}{W_{\mathrm{f}, 0}} \\
& R=\sum_{i=1}^{n} R_{i} \frac{W_{\mathrm{a}, 0 i}}{W_{\mathrm{a}, 0}}
\end{aligned}
$$

Eq. (12) is identical to the one obtained by Colakyan et al. [21] when attrition and formation of fines is negligible $\left(W_{\mathrm{a}, i}=0\right)$. Eq. (12) is then reduced in terms of weight of particles of size $i$ which have elutriated from the bed:

$W_{\mathrm{e}, i}=W_{\mathrm{b}, i}\left(1-\mathrm{e}^{-k_{i}^{*} t}\right)$

\section{Experimental}

The equipment used is shown schematically in Fig. 1. The fluidized bed of $6.4 \mathrm{~cm}$ i.d. and $1 \mathrm{~m}$ height was fitted

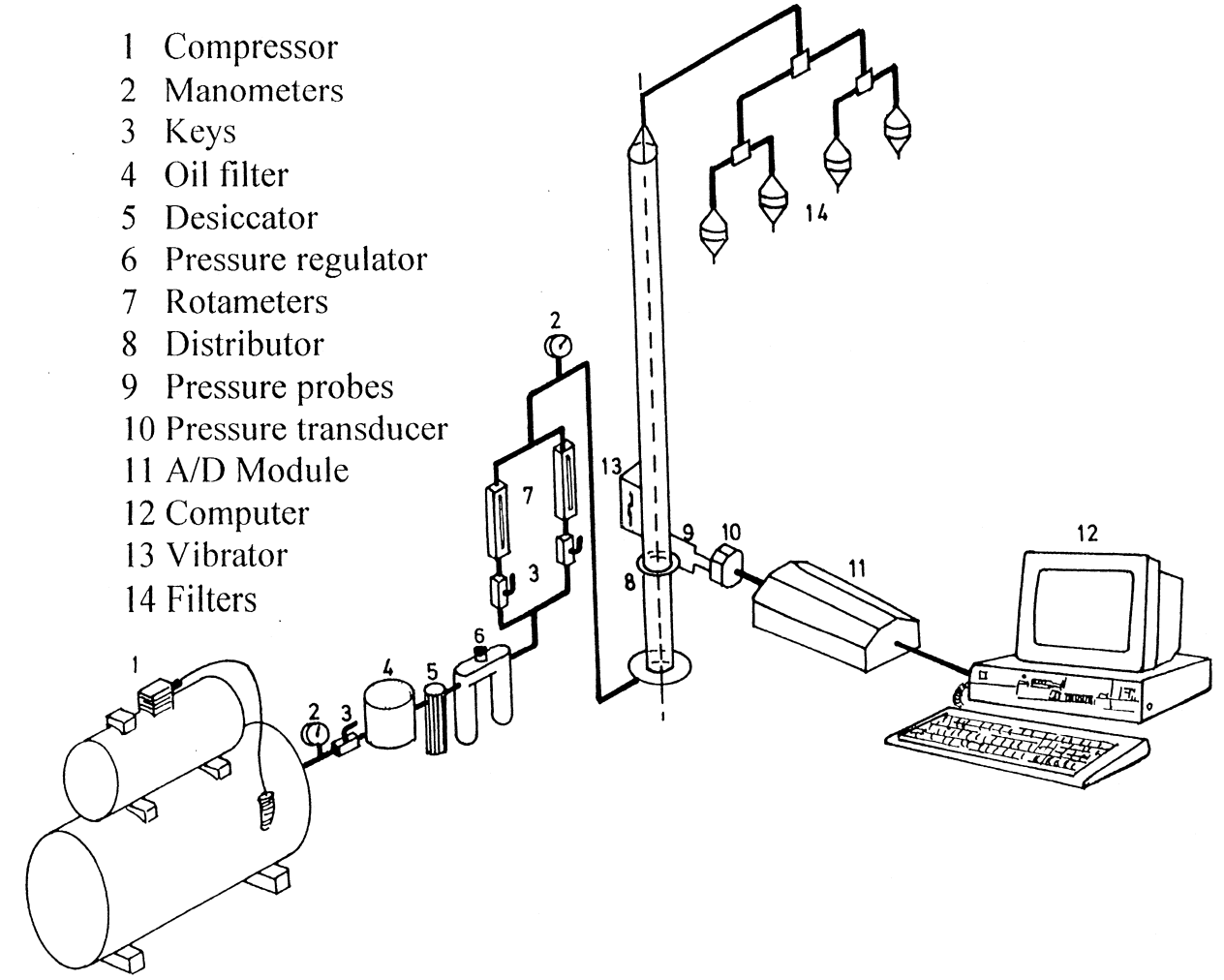

Fig. 1. Schematic diagram of experimental apparatus. 
Table 1

Relevant properties of powders used in the experiments

\begin{tabular}{llcl}
\hline & $\begin{array}{l}\text { Density } \\
\left(\mathrm{kg} \mathrm{m}^{-3}\right)\end{array}$ & $\begin{array}{l}\text { Sauter mean } \\
(\mu \mathrm{m})\end{array}$ & $\begin{array}{l}\text { Geldart } \\
\text { group }\end{array}$ \\
\hline $\mathrm{Al}_{2} \mathrm{O}_{3}$ & 3650 & 48.03 & A \\
$\mathrm{TiO}_{2}$ & 3900 & 0.72 & $\mathrm{C}$ \\
$\mathrm{CaCO}_{3}$ & 2500 & 5.10 & $\mathrm{C}$ \\
Sand & 2670 & 397.31 & B \\
\hline
\end{tabular}

with a distributor consisting of a nylon mesh screen between two perforated plates.

The top of the bed was tapered so that an abrupt increase in gas velocity was avoided. This part of the column was connected with the filters by means of an anti-static tube to prevent static deposition of the elutriation dust before filtration. The effluent dust concentrations were determined by weighing particles collected by a Whatman filter paper No. 1.

Various powders were used and Table 1 lists their major properties. The powders were tested at several velocities ranging from 0.24 to $0.61 \mathrm{~m} \mathrm{~s}^{-1}$. The flow rate of fluidizing gas was adjusted by a control valve at prescribed values with two rotameters so that the superficial gas velocities were determined.

The total pressure drop through the bed was measured with a pressure transducer, Setra C-264 which was capable of measuring pressure differences in the range of 0-6350 $\mathrm{Pa}$. All measured pressure data were treated with a data acquisition system which was connected to a computer.

\section{Experimental procedures}

Prior to each elutriation experiment, the fluidized bed was started with sand only working at high fluidization velocities in order to remove the finer sand particles.

It was observed that there was no attrition of the sand from measurements in the rank of velocities used in the test, to the low velocity of the fluid in the orifices of the distributor [31].

Various tests were done at different velocities, verifying that the mass of sand elutriated process was zero and during the generation of particles in the different test only dust particles $\left(\mathrm{CaCO}_{3}, \mathrm{TiO}_{2}\right.$ and $\left.\mathrm{Al}_{2} \mathrm{O}_{3}\right)$ were obtained.

The experiment was started and allowed to run at minimum fluidization velocities until the dust particles, which would be added between 2.5 and $5 \%$ of the bed weight, reached a good degree of mixing with the bulk (sand) bed material but being observed that the carryover of particles in the bed did not occur.

The run was started, increasing the gas velocity. The test duration varied from 60 to $90 \mathrm{~min}$ for superficial gas velocities of 0.24 to $0.61 \mathrm{~m} \mathrm{~s}^{-1}$, respectively. To avoid adherence of fines to the wall of the unit, the freeboard section was constantly vibrated gently.
After a run was completed, the powder from the absolute filter was collected, weighed and sampled. The Microtrac SRA laser scattering from Leed and Northrup was used to analyse the particle size distribution.

To measure the extent of experimental error, runs with the powders were repeated at three velocities under identical conditions. The difference in elutriation rates was negligible at low velocities and less than $9 \%$ at high fluidization velocities.

\section{Results and discussions}

All the experiments were carried out at room temperature. Two separate runs were made for each mixture of solids: (a) the measurements of pressure drop, minimum fluidization velocity and minimum bubbling velocity which allows to characterise the fluidization process [32]; and (b) the analyses of fines carryover.

Fig. 2 shows the observed pressure drop as a function of the dimensionless index of fluidization varying with gas velocities. The fluidization index FI [33] is defined as the ratio of the pressure drop over the bed to the weight of the bed per unit cross-sectional area, $A_{\mathrm{b}}$ :

$\mathrm{FI}=\frac{\Delta P \cdot A_{\mathrm{b}}}{W_{\mathrm{b}} \cdot g}$

where $W_{\mathrm{b}}$ is the mass of the bed, $\Delta P$ the pressure drop across the bed and $g$ is the gravitational constant.

Fig. 2 determines the minimum fluidization velocity, $u_{\mathrm{mf}}$, required to fluidize the powder. It is usually determined from the intersection of the two straight lines of the pressure drop vs. superficial gas velocity, generated at decreasing gas velocity.

It can be seen in the figure that the minimum fluidization velocity is smaller with vibration than without it and the fluidization index FI is slightly higher with vibration, indicating that it is very close to unity. However, it can be

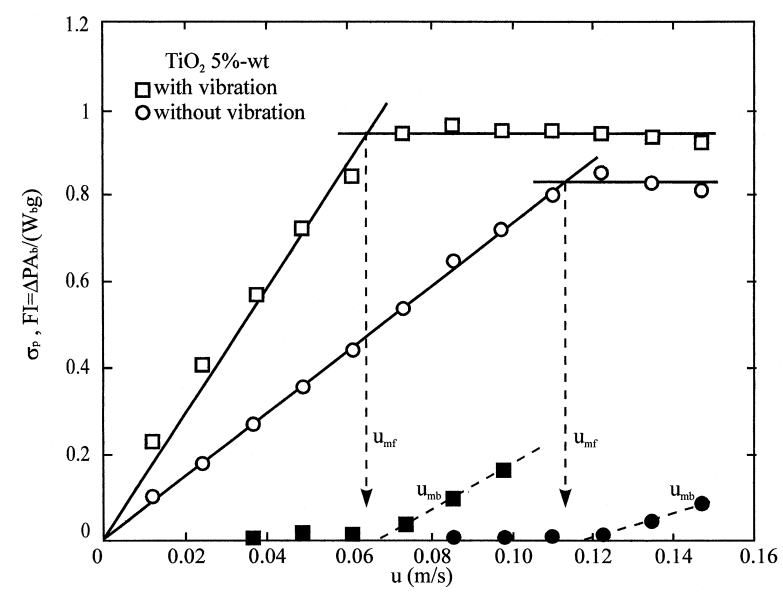

Fig. 2. Variation of fluidization index FI with gas velocities. 
Table 2

Effect of the vibration on minimum fluidization velocity and minimum bubbling velocity for the different mixtures used in the experiments

\begin{tabular}{|c|c|c|c|c|c|c|}
\hline & $\begin{array}{l}\mathrm{Al}_{2} \mathrm{O}_{3} \\
(2.5 \text { wt. } \%)\end{array}$ & $\begin{array}{l}\mathrm{CaCO}_{3} \\
(2.5 \text { wt. } \%)\end{array}$ & $\begin{array}{l}\mathrm{CaCO}_{3} \\
(5 \text { wt. } \%)\end{array}$ & $\begin{array}{l}\mathrm{TiO}_{2} \\
(2.5 \text { wt. } \%)\end{array}$ & $\begin{array}{l}\mathrm{TiO}_{2} \\
\text { (5 wt. \%) }\end{array}$ & \\
\hline With vibration & 5.12 & 5.40 & 5.58 & 6.63 & 6.89 & $u_{\mathrm{mf}}\left(\mathrm{cm} \mathrm{s}^{-1}\right)$ \\
\hline Without vibration & 9.14 & 9.80 & 10.27 & 11.00 & 11.23 & $u_{\mathrm{mf}}\left(\mathrm{cm} \mathrm{s}^{-1}\right)$ \\
\hline Without vibration & 9.27 & 9.97 & 10.38 & 11.51 & 11.77 & $u_{\mathrm{mb}}\left(\mathrm{cm} \mathrm{s}^{-1}\right)$ \\
\hline
\end{tabular}

observed that the loss of charge increases with vibration, thus, indicating a better gas/solid contacting in the bed and more complete suspension of the particles. In this way, the channelling diminishes or disappears. Similar results were reported by Jaraiz et al. [12].

The minimum fluidization velocities and the minimum bubbling velocities for the different materials are shown in Table 2 . The minimum bubbling velocities were calculated using the variation of the standard deviation of pressure drop. One may see that the minimum bubbling velocity $u_{\mathrm{mb}}$ is roughly equal to the minimum fluidization velocities and it is a characteristic of Geldart-B particles which still remain in the fluidized bed (sand) even when they are mixed with fine powder $\left(\mathrm{CaCO}_{3}, \mathrm{TiO}_{2}\right.$ and $\left.\mathrm{Al}_{2} \mathrm{O}_{3}\right)$.

In a fluidized bed aerosol generator, the understanding of the breakage behaviour of the powder material is made difficult by the interaction and competition between various causes of breakage [14]. In the present investigation involving fluidization of non-reacting particles, any breakage of particles can be assumed to be due to purely hydrodynamic forces within the bed.

Since the fluidization velocities of large particles are much larger than the terminal velocities of fine particles; only elutriable fines are entrained by the gas flow. All these fine particles so entrained were collected by a set of filters.

Fig. 3 shows the cumulative mass of $\mathrm{CaCO}_{3}(5 \%)$ powder entrained from the bed. These experimental data suggest a nonlinear rate of increase in the mass of fines

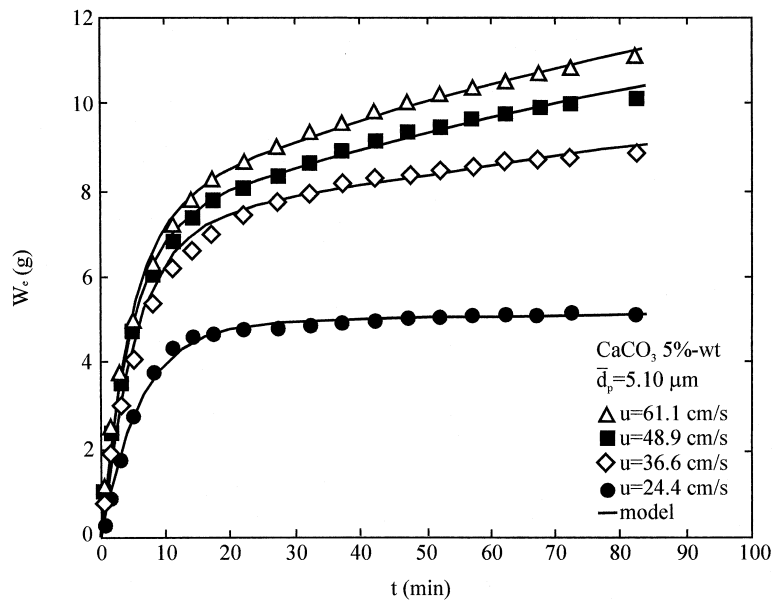

Fig. 3. Cumulative mass of entrained powder $\left(\mathrm{CaCO}_{3}, 5 \mathrm{wt} . \%\right)$. generated as the function of operating time. The accumulation of mass $W_{\mathrm{e}}$ of entrained particles starts rapidly and then gradually reduces as operation proceeds, becoming eventually zero if the experiment is carried out for a long time.

We have observed a relatively high formation of fines during the initial period of fluidization due to the removal of sharp corners and edges of the attriting particles. Similar observations have been reported previously by Ayazi Shamlou et al. [14] and Santana et al. [34].

In general, it is seen that the accumulation of mass $W_{\mathrm{e}}$ of entrained particles increases with increasing the gas velocity. Fig. 3 illustrates that for a gas velocity of $0.24 \mathrm{~m}$ $\mathrm{s}^{-1}$ the breakage of fine particles, which is expected to be by attrition, is smaller than for other velocities, thus, showing the importance of pure hydrodynamic forces within the bed.

In Fig. 3, our modelling has been applied to the experimental conditions and compared with experimental results $\left(\mathrm{CaCO}_{3}, 5 \%\right)$. The figure illustrates the predicted value of the cumulative mass with the experimental measurements of $\mathrm{CaCO}_{3}$ from different operating conditions. The results demonstrate favourable agreement between the experimental data and model predictions.

Fig. 4 shows the cumulative mass of $\mathrm{Al}_{2} \mathrm{O}_{3}$ (2.5 wt.\%) powder entrained from the bed. It can be seen that the cumulative mass of entrained particles starts rapidly and almost the initial mass of fine particles $(7.5 \mathrm{~g})$ are entrained by gas flow in a few minutes, this indicates the

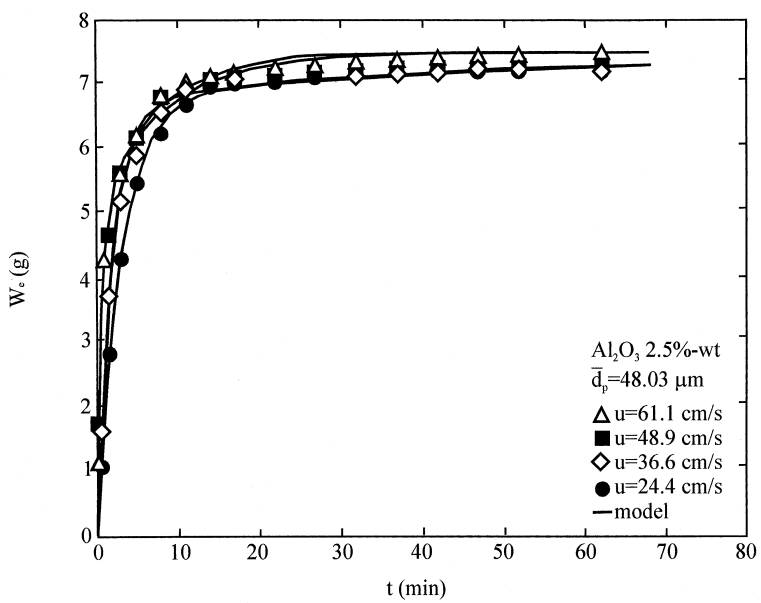

Fig. 4. Cumulative mass of entrained powder $\left(\mathrm{Al}_{2} \mathrm{O}_{3}, 2.5\right.$ wt.\%). 
poor cohesiveness of $\mathrm{Al}_{2} \mathrm{O}_{3}$ This poor cohesiveness of $\mathrm{Al}_{2} \mathrm{O}_{3}$ is considered to have led to higher values of the elutriation rate constant and attrition rate constant.

Fig. 5 shows the cumulative mass of large silicon particles with $15 \%$ of fine silicon particles vs. time for various gas velocities obtained by Liu and Kimura [19]. This experimental data has been compared with the suggested model that describes the entrainment comprising elutriation and attrition in a fluidized bed which incorporates the following assumptions to describe the elutriation and attrition process:

- The generation of fines by attrition is a nonlinear function of time.

- Fine particles in the bed are in one of the following forms.

-elutriable freely moving fines

-agglomerates of fines and fines attached to large particles

Confirming that we have a favourable agreement between the experimental data obtained in this work as well as those reported by Liu and Kimura [19] and predicted values by the model.

Fig. 6 compares the percentage of the initial mass of elutriable fine particles in the bed at different gas velocities for the various powders tested. In this figure, an increase in the percentage of free fines when the fluidization velocities increase can be observed. There are great differences between the three compounds studied $\left(\mathrm{CaCO}_{3}\right.$, $\mathrm{TiO}_{2}$ and $\mathrm{Al}_{2} \mathrm{O}_{3}$ ) with respect to their fluidization behaviour

These differences are mainly due to the fact that the percentage of the initial mass of elutriable fine particles $W_{\mathrm{f}, 0} / W_{\mathrm{b}, \mathrm{f}}$ for the group $\mathrm{C}$ powder $\left(\mathrm{TiO}_{2}\right)$ is markedly lower at low superficial gas velocities (effect of interparticle adhesion forces), whereas at high velocities this percentage increases up to $15 \%$.

In the case of $\mathrm{CaCO}_{3}$, it can be observed that for high velocities, the percentage of free fines is about $50 \%$. This

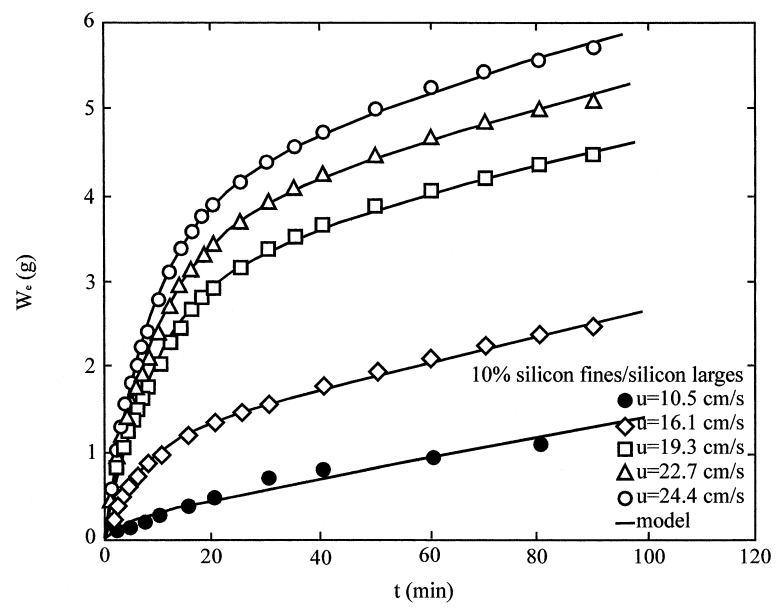

Fig. 5. Cumulative mass of entrained powder from $10 \mathrm{wt} \%$ silicon fines/silicon larges from Ref. [19].

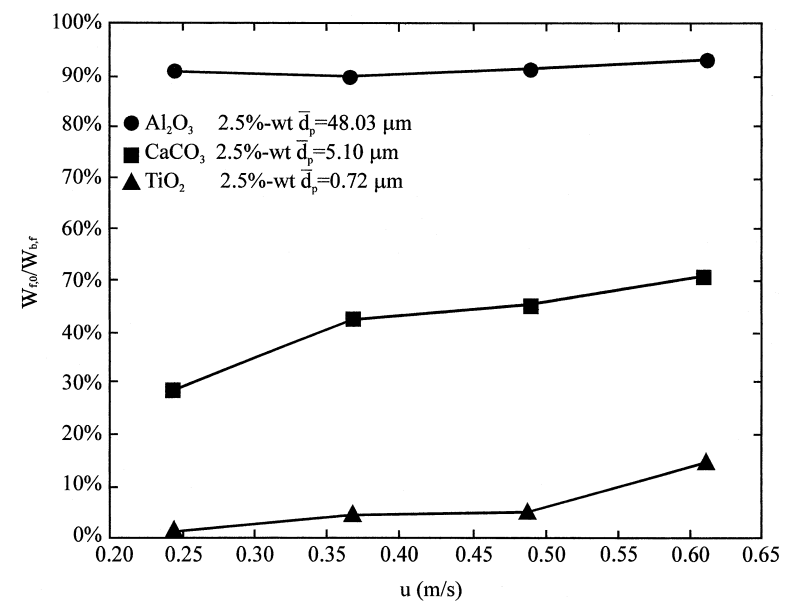

Fig. 6. Percentage of initial mass of elutriable fine particles vs. gas velocity.

is due to the fact that in the group $\mathrm{C}$ powders the interparticle forces are substantially larger than the hydrodynamic forces and the gas can not readily separate the powder from the larger particles in the bed (sand). A clear difference is noticed for group A powders, represented by $\mathrm{Al}_{2} \mathrm{O}_{3}$ confirming that the percentage of free fines is practically constant and independent of the fluidization velocity, keeping this as about $90 \%$. Therefore, its poor cohesiveness is obvious because the interparticle forces in group A powders are small compared with the hydrodynamic forces acting in the fluidized bed.

Fig. 7 compares the overall elutriation rate constant at different gas velocities for various materials. The overall elutriation rate constant $\mathrm{k}$, increases with gas velocities, and is larger for $\mathrm{Al}_{2} \mathrm{O}_{3}$ than for $\mathrm{TiO}_{2}$, confirming that higher gas velocities generate more elutriable fines. For gas velocities larger than about $0.35 \mathrm{~m} \mathrm{~s}^{-1}$ the overall elutriation rate constant has a noticeable increase with the fluidization velocity, specially for $\mathrm{Al}_{2} \mathrm{O}_{3}$.

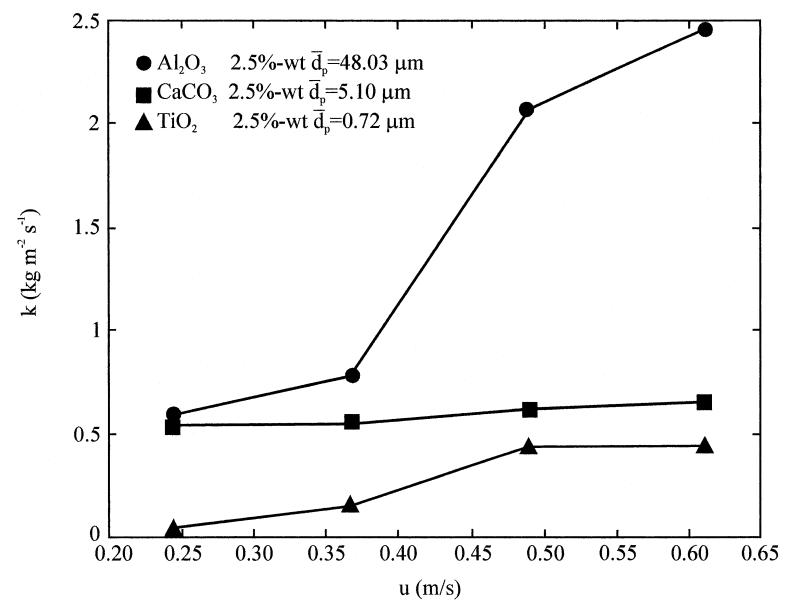

Fig. 7. Elutriation rate constant vs. gas velocity. 
Fig. 8 shows values of the overall attrition rates, $R$, with gas velocities which presents a similar feature to that of the overall elutriation rate constant shown in Fig. 7. The overall attrition rate is quite independent of the fluidization velocity except for $\mathrm{Al}_{2} \mathrm{O}_{3}$ as higher velocities. Due to an increasing velocity, the kinetic energy transferred from the gas to the bed increases. It can also be observed that the slope of the overall attrition constant increases from the most cohesive material $\left(\mathrm{TiO}_{2}\right)$ to the least cohesive $\left(\mathrm{Al}_{2} \mathrm{O}_{3}\right)$ : slope is a clear indicator of the cohesiveness of the tested materials. Fig. 8 compares the overall attrition rate of the three powders and clearly, the $\mathrm{Al}_{2} \mathrm{O}_{3}$ powder shows a distinct behaviour. This phenomenon probably corresponds to the progressive abrasion of surface asperities and also because the energy causes the attrition to depend upon the efficiency of energy exchange between the fluid and the particles in the bed and on the surface cohesion force of single particles.

This finding is in line with the previous results given by Ray et al. [13], Ayazi Shamlou et al. [14] where, according to the model, the least cohesive dust will be the one with a higher attrition rate constant. These results were obtained in test in which an increase in the percentage of binder produced a reduction of the attrition constant, so the forces of adhesion of fines changed and Smolders and Baeyens [11] where it is important to stress the fluid-dynamic-induced forces acting on the particles and the importance of the adhesion effects on fine particles.

Finally, according to Ray et al. [13], various attrition studies are contradictory about the effect of the particle attrition rate. Ayazi Shamlou et al. [14] consider that it is important to research the particle breakage as results of particle to particle or particle to wall interaction. Future experimental work will be aimed towards identifying what causes particle agglomeration. We have observed that the entrainment of smaller particles at low air velocities needs further investigations due to the adhesion effects.

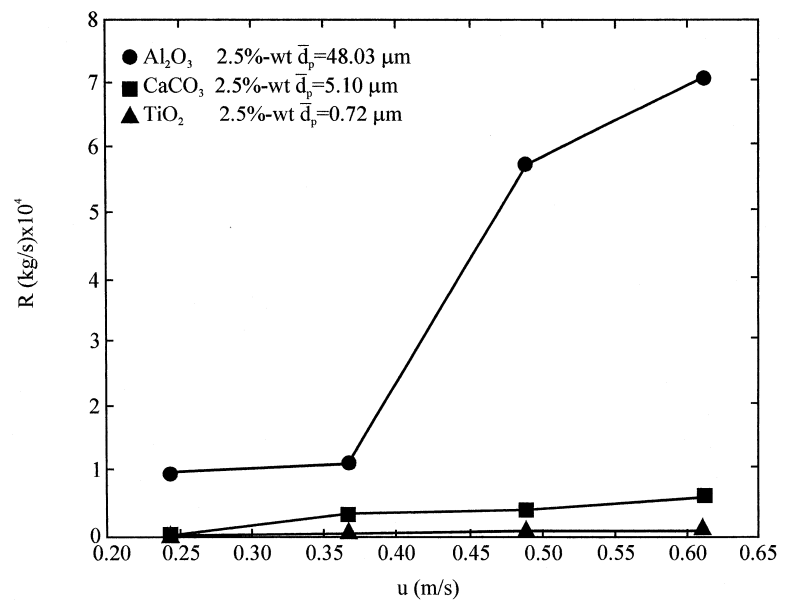

Fig. 8. Attrition rate vs. gas velocity.

\section{Conclusions}

Experimental results are presented on the elutriation of Geldart A and C particles of various densities, fluidized batchwise at air velocities between 0.14 and $0.61 \mathrm{~m} \mathrm{~s}^{-1}$. The attrition rate and elutriation rate constant increase with gas velocities and this effect is much more noticeable in the case of Geldart group $\mathrm{A}\left(\mathrm{Al}_{2} \mathrm{O}_{3}\right)$ powders.

A new model was proposed to describe the entrainment comprising elutriation and attrition as a nonlinear function of time considering that the modelling of the attrition process due to purely hydrodynamic forces assumes that the fine particles are in the following forms: (a) elutriable freely moving fines, (b) agglomerates of fines and fines attached to large particles. The applicability of this model has been verified with the experimental data obtained in this work and as reported by others.

The new model presented herein is preferable to other literature because it more realistically represents the actual physical elutriation process in a fluidized bed.

The entrainment rate at low air velocities is strongly reduced by interparticle adhesion forces. These adhesion effects and a more accurate prediction of particle agglomeration need further investigation.

\section{List of symbols}

$A_{\mathrm{b}} \quad$ cross-sectional area of a fluidized bed $\left(\mathrm{m}^{2}\right)$

$\underline{d}_{i} \quad$ particle diameter $(\mu \mathrm{m})$

$\bar{d}_{\mathrm{p}} \quad$ Sauter mean diameter $(\mu \mathrm{m})$

$f_{\text {err }} \quad$ objective function $\left(\mathrm{kg}^{2}\right)$

FI fluidization index

$g$

$k$

$k_{i}$

$k_{i}^{*} \quad$ elutriation velocity constant for particles of size $i\left(\mathrm{~s}^{-1}\right)$

time (s)

$t$

$u$

$u_{\mathrm{mb}}$

$u_{\mathrm{mf}}$

$R$

$R_{i}$

$R_{i}^{*}$

$W_{\mathrm{a}, i}$

$W_{\mathrm{a}, 0 i}$

$W_{\mathrm{b}}$

$W_{\mathrm{b}, \mathrm{f}}$

$\mathrm{p} W_{\mathrm{b}, i}$

$W_{\mathrm{e}, i}$

overall elutriation rate constant $\left(\mathrm{kg} \mathrm{m}^{-2} \mathrm{~s}^{-1}\right)$

elutriation rate constant for particles of size $i$ $\left(\mathrm{kg} \mathrm{m}^{-2} \mathrm{~s}^{-1}\right)$

superficial velocity of fluidizing gas $\left(\mathrm{m} \mathrm{s}^{-1}\right)$ minimum bubbling velocity $\left(\mathrm{m} \mathrm{s}^{-1}\right)$

minimum fluidization velocity $\left(\mathrm{m} \mathrm{s}^{-1}\right)$

overall attrition rate constant $\left(\mathrm{kg} \mathrm{s}^{-1}\right)$

attrition rate constant for particles of size $i(\mathrm{~kg}$ $\mathrm{s}^{-1}$ )

attrition velocity for particles of size $i\left(\mathrm{~s}^{-1}\right)$

mass of agglomerates fines of size $i$ remaining in the bed at any time $(\mathrm{kg})$

initial mass of agglomerates fines of size $i(\mathrm{~kg})$

initial mass particles in the bed $(\mathrm{kg})$

initial mass of fine particles in the bed $(\mathrm{kg})$

initial mass of particles size $i$ in the bed $(\mathrm{kg})$

cumulative mass of fine particles carried out of the bed $(\mathrm{kg})$ 


$\begin{array}{ll}W_{\mathrm{f}, i} & \begin{array}{l}\text { mass of elutriable freely moving fines of size } i \\ \text { remaining in the bed at any time }(\mathrm{kg})\end{array} \\ W_{\mathrm{f}, 0 i} & \begin{array}{l}\text { initial mass of elutriable freely moving fines of } \\ \text { size } i(\mathrm{~kg})\end{array} \\ W_{i} & \begin{array}{l}\text { mass of fine particles of size } i \text { remaining in the } \\ \text { bed at any time }(\mathrm{kg})\end{array} \\ \Delta P & \begin{array}{l}\text { apressure drop }(\mathrm{Pa})\end{array}\end{array}$

\section{Acknowledgements}

The financial support from CICYT of the Spanish Government is appreciated (project number AMB95-0200).

\section{References}

[1] V. Henríquez, A. Lozano, A. Macías-Machín, Proc. I International Symposium on Filtration and Separation, Salamanca, España, 1995, p. 98.

[2] D. Hyman, Master's Thesis, Massachusetts Inst. Tech., Cambridge, USA, 1952.

[3] M. Leva, Chem. Eng. Prog. 47 (1951) 39.

[4] G.L. Osberg, D.H. Charlesworth, Chem. Eng. Prog. 47 (1951) 566.

[5] D. Kunii, O. Levenspiel, Fluidization Engineering, ButterworthHeinemann, USA, 1991, pp. 165-177.

[6] D. Geldart, J. Culinan, S. Georghiades, D. Gilvray, D.J. Pope, Trans. Inst. Chem. Eng. 57 (1979) 269.

[7] C.Y. Wen, L.H. Chen, AIChE J. 28 (1982) 117.

[8] J.G. Yates, D. Newton, Chem. Eng. Sci. 41 (1986) 801.

[9] D. Geldart, N. Harnby, A.C. Wong, Powder Technol. 37 (1987) 25.

[10] J. Baeyens, D. Geldart, S.Y. Wu, Powder Technol. 71 (1992) 71.
[11] K. Smolders, J. Baeyens, Powder Technol. 92 (1997) 35.

[12] E. Jaraiz, S. Kimura, O. Levenspiel, Powder Technol. 72 (1992) 23.

[13] Y. Ray, T. Jiang, C.Y. Wen, Powder Technol. 49 (1987) 193.

[14] P. Ayazi Shamlou, Z. Liu, J.G. Yates, Chem. Eng. Sci. 45 (1990) 809.

[15] U. Arena, M. D’Amore, L. Massimilla, AIChE J. 29 (1983) 40.

[16] D. Bortzmeyer, J.C. Goimard, Powder Technol. 86 (1996) 163.

[17] N.K. Yadav, B.D. Kulkarni, L.K. Doraiswamy, Ind. Eng. Chem. Res. 33 (1994) 2412.

[18] R. Chirone, M. D’Amore, L. Massimilla, A. Mazza, AIChE J. 31 (1985) 812.

[19] Y.D. Liu, S. Kimura, Powder Technol. 75 (1993) 189.

[20] D. Bénoni, C.L. Briens, T. Baron, E. Duchesne, T.M. Knowlton, Powder Technol. 78 (1994) 33.

[21] M. Colakyan, N. Catipovic, G. Jovanovic, T.J. Fitzgerald, AIChE Symp. Ser. 77 (1981) 66.

[22] O. Levenspiel, Chemical Reactor Omnibook, OSU Book Stores, Corvallis, OR, USA, 1989.

[23] C.Y. Wen, R.F. Hashinger, AIChE J. 6 (1960) 220.

[24] B.W. Overturf, G.V. Reklaitis, AIChE J. 29 (1983) 813.

[25] D.M. Bachovchin, J.M. Beer, A.F. Sarofim, AIChE Symp. Ser. 77 (1981) 76.

[26] F.E. Milioli, P.J. Foster, Powder Technol. 83 (1995) 233.

[27] L.S. Fan, R.C. Srivastava, Chem. Eng. Sci. 36 (1981) 1091.

[28] A. Kokkoris, R. Turton, Powder Technol. 84 (1995) 39.

[29] S.M. Tasirin, D. Geldart, Powder Technol. 95 (1998) 240.

[30] J.E. Denis Jr., D.J. Woods, in: Wouk (Ed.), New Computing Environments: Microcomputers in Large-Scale Computing, SIAM, New York, USA, 1987, p. 116.

[31] H. Arastoopour, C.Y. Chen, Powder Technol. 36 (1983) 99.

[32] D. Geldart, Powder Technol. 7 (1973) 285.

[33] E. Marring, A.C. Hoffmann, L.P.B.M. Janssen, Powder Technol. 70 (1994) 1.

[34] D. Santana, V. Henríquez, A. Macías-Machín, Proc. II European Conference on Fluidization, Bilbao, Spain, 1996, p. 429. 